\title{
Endogenous mouse mammary tumor viruses (Mtv): new roles for an old virus in cancer, infection, and immunity
}

\section{Michael P. Holt, Ethan M. Shevach and George A. Punkosdy *t}

Laboratory of Immunology, National Institute of Allergy and Infectious Diseases, National Institutes of Health, Bethesda, MD, USA

Edited by:

lyoko Katoh, University of Yamanashi, Japan

\section{Reviewed by:}

Shridar Ganesan, University of

Medicine and Dentistry of New

Jersey, USA

Xiaoping Zhang, Mount Sinai School

of Medicine, USA

\section{${ }^{*}$ Correspondence:}

George A. Punkosdy, Department of Microbiology and Immunology,

Emory University, 1510 Clifton Road,

Room G-211, Atlanta, GA 30322, USA

e-mail: george.punkosdy@emory.edu

${ }^{\dagger}$ Present address:

George A. Punkosdy, Department of Microbiology and Immunology,

Emory University, Atlanta, GA, USA
Mouse MammaryTumor Viruses are beta-retroviruses that exist in both exogenous (MMTV) and endogenous (Mtv) forms. Exogenous MMTV is transmitted via the milk of lactating animals and is capable of inducing mammary gland tumors later in life. MMTV has provided a number of critical models for studying both viral infection as well as human breast cancer. In addition to the horizontally transmitted MMTV, most inbred mouse strains contain permanently integrated Mtv proviruses within their genome that are remnants of MMTV infection and vertically transmitted. Historically, Mtv have been appreciated for their role in shaping the $T$ cell repertoire during thymic development via negative selection. In addition, more recent work has demonstrated a larger role for Mtv in modulating host immune responses due to its peripheral expression. The influence of Mtv on host response has been observed during experimental murine models of Polyomavirus- and ESb-induced lymphoma as well as Leishmania major and Plasmodium berghei ANKA infection. Decreased susceptibility to bacterial pathogens and virus-induced tumors has been observed among mice lacking all Mtv. We have also demonstrated a role for Mtv Sag in the expansion of regulatory T cells following chronic viral infection. The aim of this review is to summarize the latest research in the field regarding peripheral expression of Mtv with a particular focus on their role and influence on the immune system, infectious disease outcome, and potential involvement in tumor formation.

Keywords: endogenous retrovirus, mouse mammary tumor virus, immune system, infection, cancer

\section{INTRODUCTION}

The integration of viral nucleic acid sequences into the host genome is a hallmark of the retroviral life cycle. Integration in somatic cells results in infection of the host and transmission of the virus requires the production of infectious viral particles that are passed on to a new host horizontally. On the other hand, integration in the germ line results in the generation of endogenous retroviruses that become an inheritable part of the host genome. Endogenous retroviruses constitute a significant fraction of various vertebrate genomes, including both human and mouse (1-3). Two of the more widely studied endogenous retroviruses within the mouse genome are the murine leukemia virus (4) and the mouse mammary tumor virus (5), which exist in both exogenous (MMTV) and endogenous (Mtv) forms. While the exogenous MMTV has been extensively studied for its role in the establishment and transmission of mammary carcinomas $(6,7)$, much less remains known about the influence of the endogenous $M t v$ on the host. The aim of this review is to focus on recent advances in understanding the role of endogenous $M t v$, particularly in relation to cancer, infection, and immunity.

Mice inherit Mtv that have integrated into the host genome according to Mendelian inheritance patterns. Greater than 30 different endogenous Mtv have been identified (8). The most common inbred laboratory mice contain between two and eight copies of endogenous Mtv, the majority of which are shared between several different strains (Table 1) $(5,9)$. Certain wild-derived (feral) strains of mice, including PERA/Ei and Czech II, are completely devoid of endogenous Mtv. Only a few of the endogenous $M t v$, including $M t v-1,-2$, and -4 have retained the ability of forming infectious viral particles $(10,11)$. Some proviruses, including $M t v-2$, are capable of both exogenous and endogenous transmission (12).

Endogenous Mtv maintain a genetic structure similar to their exogenous MMTV counterparts. For a detailed description of this genetic makeup see the review by Ross (13). Briefly, MMTV is a type B retrovirus of the Retroviridae family that contains a $9 \mathrm{~kb}$ RNA genome encoding virion capsid (Gag) proteins, reverse transcriptase and integrase enzymes necessary for viral replication (Pol), and envelope (Env) proteins used for viral entry. Like all other retroviruses, MMTV is flanked by $5^{\prime}$ and $3^{\prime}$ long terminal repeats (LTRs). The $3^{\prime}$ LTR of MMTV contains an open reading frame that encodes the viral accessory protein, superantigen (Sag), a type 2 transmembrane glycoprotein $(14,15)$. More recent data has demonstrated that the $3^{\prime}$ LTR of MMTV also encodes another accessory protein, regulatory of export of MMTV (Rem). Rem is required for efficient nuclear export of unspliced viral RNA via interaction with a Rem-responsive element present in MMTV RNA (16). Both Sag and Rem are encoded by alternatively spliced mRNAs. Rem is related to the human immunodeficiency virus (HIV) Rev protein, thus making MMTV a complex retrovirus $(17,18)$. Endogenous $M t v$ have accumulated various point mutations or deletions in their proviral genome (19-21). However, 
Table 1 | Expression of endogenous Mtv among common mouse strains.

\begin{tabular}{|c|c|c|c|c|}
\hline Mouse strain & Mtv provirus & H-2 & I-A & I-E \\
\hline $\mathrm{A} / \mathrm{J}$ & $6,8,13$ & $\mathrm{H}-2^{\mathrm{a}}$ & $I-A^{k}$ & $I-E^{k}$ \\
\hline $\mathrm{AKR} / \mathrm{J}$ & $7,8,9,17,23,30$ & $\mathrm{H}-2^{\mathrm{k}}$ & $I-A^{k}$ & $I-E^{k}$ \\
\hline $\mathrm{BALB} / \mathrm{cJ}$ & $6,8,9$ & $H-2^{d}$ & $I-A^{d}$ & $I-E^{d}$ \\
\hline $\mathrm{C} 3 \mathrm{H} / \mathrm{HeJ}$ & $1,6,8,11,14$ & $\mathrm{H}-2^{\mathrm{k}}$ & $\mathrm{I}-\mathrm{A}^{\mathrm{k}}$ & $I-E^{k}$ \\
\hline C57BL/6J & $8,9,17$ & $\mathrm{H}-2^{\mathrm{b}}$ & $I-A^{b}$ & Null \\
\hline C58/J & $3,7,17$ & $\mathrm{H}-2^{\mathrm{k}}$ & $I-A^{k}$ & $I-E^{k}$ \\
\hline CBA/CaJ & $8,9,14$ & $\mathrm{H}-2^{\mathrm{k}}$ & $1-A^{k}$ & $I-E^{k}$ \\
\hline $\mathrm{CBA} / \mathrm{J}$ & $6,7,8,9,14,17$ & $\mathrm{H}-2^{\mathrm{k}}$ & $I-A^{k}$ & $I-E^{k}$ \\
\hline $\mathrm{DBA} / 2 \mathrm{~J}$ & $1,6,7,8,11,13,14,17$ & $H-2^{d}$ & $I-A^{d}$ & $1-E^{d}$ \\
\hline SJL/J & $8,29,31$ & $\mathrm{H}-2^{\mathrm{S}}$ & $\mathrm{I}-\mathrm{A}^{\mathrm{s}}$ & Null \\
\hline
\end{tabular}

almost all Mtv have maintained functional Sag expression. While other viral proteins play important roles (especially in terms of viral particle assembly for MMTV), it is the expression of Sag by both MMTV and Mtv that has been the most extensively studied. Sag expression plays an important role in the biology of both forms of the virus that is best understood from a historical perspective.

\section{IMPORTANCE OF SAG IN EXOGENOUS MMTV INFECTION}

As early as 1936, it was observed that certain strains of inbred mice at Jackson Laboratories (ME, USA) displayed an inherent susceptibility to spontaneous mammary carcinomas. The incidence of tumor development ranged from high, intermediate, and low depending on the particular strain of mouse (22). It became readily apparent that the cancer-inducing agent was maternally transmitted and present in milk, and subsequent experiments demonstrated that the causative agent was a virus. Further work led to the discovery and identification of MMTV, originally known as Bittner virus, as the causative agent (23).

In order for MMTV to reach the mammary gland, a complex series of events must occur in which the virus requires and subverts cells of the immune system, particularly B and T cells, to establish infection. The initial site of milk-borne MMTV infection is the gut-associated lymphoid tissue, specifically the Peyer's patches, where B cells represent the initial target cell (24). The initial round of $B$ cell infection and activation occurs as a result of the interaction between MMTV Env protein and Toll-like receptor 4 (25). The ability of MMTV to disseminate from the gut to the mammary gland is dependent upon this expression of the virally encoded Sag (26). Infected B cells present Sag in conjunction with the major histocompatibility complex (MHC) class II proteins to $\mathrm{CD}^{+} \mathrm{T}$ cells bearing a reactive $\mathrm{T}$ cell receptor (TCR) $\mathrm{V} \beta$ chain. A polymorphic region within the carboxyl terminus of MMTV Sag determines the TCR V $\beta$ domain specificity (27-29). Different MHC class II alleles display strikingly disparate Sag presentation capabilities, with MHC class II I-E inducing the most efficient presentation to T cells (30). Stimulation of Sag-reactive $\mathrm{CD}^{+} \mathrm{T}$ cells leads to their activation and production of various cytokines and chemokines. In addition, activated $\mathrm{T}$ cells upregulate CD40 ligand (CD40L), which binds to the CD40 receptor on $\mathrm{B}$ cells to further activate them (31). Such activation stimulates and recruits additional $\mathrm{B}$ and $\mathrm{T}$ cells, thereby resulting in further immune cell activation and the subsequent amplification of a reservoir of MMTV infected cells (32). Infected B cells then travel to the developing mammary gland and thereby enable the virus to infect the tumor-susceptible target organ. The critical requirement for an infected lymphocyte population during MMTV infection and dissemination is demonstrated by the resistance of nude mice which lack a functional T cell compartment (33), neonatal thymectomized mice (34), mice lacking Sag-reactive T cells (26), or B cell deficient mice (24) to milk-borne transmission of MMTVinduced tumor development. Mice with inefficient presentation of MMTV Sag due to MHC class II mutations are also resistant to viral infection (35).

Since MMTV does not encode an oncogene, mammary tumorigenesis occurs after insertion of proviral DNA near cellular protooncogenes and activation of transcription (36-38). Analysis of genes activated by integration of the MMTV provirus using the viral genome as a molecular tag enabled the identification of a number of MMTV-tagged genes. Of these genes, the Wnt [relating to the Drosophilia segmented polarity gene wingless $(\mathrm{Wg})]$ and fibroblast growth factor $(F g f)$ family of genes represent major targets of mutagenic effects $(36,39-41)$. However, the frequency of gene activation responsible for mammary tumor development is dependent on both the strain of the mouse and the virus.

\section{HISTORY OF ENDOGENOUS Mtv}

Retrospectively, evidence of Mtv Sag expression was first observed in experiments demonstrating non-reciprocal lymphocyte activation/proliferation in mixed lymphocyte cultures from MHCidentical strains of mice (42). Before it was known that Mtv Sag was the culprit, the antigens responsible for inducing lymphocyte activation/proliferation were termed minor lymphocyte stimulating $(\mathrm{Mls})$ antigens. For example, $M l^{a}{ }^{a}$ expressed by DBA/ 2 mice results in $\mathrm{T}$ cell activation of BALB/c splenocytes when co-cultured. Once monoclonal antibodies to the $\mathrm{V} \beta$ regions of the TCR were made available, it became apparent that $M l s^{a}$ resulted in the activation of $\mathrm{BALB} / \mathrm{c}$ T cells expressing $\mathrm{V} \beta 6$ and that $\mathrm{V} \beta 6^{+} \mathrm{T}$ cells were largely absent in the repertoire of DBA/2 mice. Subsequent genetic studies linked various $M l s$ antigens to $M t v$ loci (43-46) and Sag as the element responsible for $\mathrm{V} \beta$-specific $\mathrm{T}$ cell interaction $(14,15)$. Therefore, an important consequence of Mtv Sag expression is the ultimate alteration of the peripheral adaptive $\mathrm{T}$ cell repertoire mediated by intrathymic deletion of Sag-reactive T cells, the extent and kinetics of which vary depending on the specific Sag (47-49). For example, the Sag associated with $M t v-7$ stimulates and deletes $\mathrm{T}$ cells bearing V $\beta 6,7,8.1$, and $9(50,51)$, while that of $M t v-9$ induces complete deletion of TCR V $\beta 5,11$, and 12 (44, $46,52)$. Table 2 provides the chromosomal location and TCR V $\beta$ specificity/deletion for a few of the more commonly encountered endogenous Mtv among different mouse strains $(53,54)$.

The fact that endogenous retroviruses in general, and Mtv in specific remain present in high percentage within the host genome over a long portion of evolution would provide the opportunity for interaction with host genes and subsequent influence of cellular function. Although a large portion of such proviruses no longer encode for functional products, thereby supporting the idea that these endogenous retroviruses are simply genomic 
Table 2 |TCR V $\beta$ specificity and deletion by endogenous Mtv.

\begin{tabular}{lcl}
\hline Mtv provirus & Chromosome & TCR V $\beta$ specificity/deletion \\
\hline$M t v-1$ & 7 & 3 \\
$M t v-2$ & 18 & 14,15 \\
$M t v-3$ & 11 & 3,17 \\
$M t v-6$ & 16 & $3,5,17$ \\
$M t v-7$ & 1 & $6,7,8.1,9$ \\
$M t v-8$ & 6 & 11,12 \\
$M t v-9$ & 12 & $5,11,12,17$ \\
$M t v-11$ & 14 & $11,12,17$ \\
$M t v-13$ & 4 & 3,17 \\
\hline
\end{tabular}

This list is not comprehensive of all Mtv.

"fossils," there do exist viral elements that have retained activity. The question is therefore what is the evolutionary role or advantage for maintaining these proviruses within the genome? One hypothesis that has been proposed is that Mtv are retained by certain mouse strains to serve as an evolutionary means of protection against exogenous milk-borne MMTV infection and MMTV-induced mammary tumors (55). This protection would result from the deletion of $M t v$-encoded Sag-specific $\mathrm{T}$ cells and the subsequent loss of a reactive pool of $\mathrm{T}$ cells necessary for infection. In support of this idea, the transgenic expression of the Sag gene of the $\mathrm{C} 3 \mathrm{H}$ strain of MMTV has been shown to protect against exogenous MMTV encoding the same Sag specificity (26). However, it is unlikely that this is the only evolutionary role for endogenous $M t v$, since wild-derived mice lacking $M t v$ are not overwhelmed by mammary carcinomas. Therefore, the question remains, what evolutionary advantage does the maintenance of these endogenous proviral genes impart to the mouse? A number of models have demonstrated that $M t v$ have the capacity to modulate the immune response, thereby providing either a selective disadvantage or advantage in regards to cancer, infection, and immunity. Some of these models require Sag expression and some may require other components of the proviral genome via mechanisms that are not fully understood.

\section{INFLUENCE OF ENDOGENOUS Mtv ON CANCER}

Evidence exists that $M t v$ can influence the development of MMTVinduced mammary carcinomas via a mechanism that does not require interaction with $\mathrm{CD} 4^{+} \mathrm{T}$ cells expressing a Sag-reactive TCR V $\beta$ region. A number of mouse strains, including $\mathrm{GR}, \mathrm{C} 3 \mathrm{H}$, BR6, and R111 have been selectively inbred for a high incidence of mammary tumors due to their transmission of MMTV to offspring via milk. Two of these strains, GR and $\mathrm{C} 3 \mathrm{H}$, additionally contain endogenous copies of $M t v$ that also generate infectious viral particles. Among weanlings of GR mice, the incidence of pregnancy-independent tumors occurs at a similar frequency whether nursed on GR mothers or foster-nursed on MMTVfree mothers (56). Mtv-2 was later identified as the dominant gene responsible for tumor development as well as responsible for the expression of MMTV within the milk of GR mice. When $\mathrm{C} 3 \mathrm{H}$ mice are freed of their corresponding exogenous $\mathrm{C} 3 \mathrm{H}$ MMTV via foster-nursing, mammary tumors still develop, yet with varying incidence and increased latency. This tumor development was determined to be dependent on the expression of Mtv-1 (10).

Another tumor model where $M t v$ has been shown to be important is infection with Polyomaviruses (PyVs) - a family of small non-enveloped, double-stranded DNA viruses with potent oncogenic capacity to induce epithelial and mesenchymal cell-derived tumors (57). Susceptibility to PyV-induced tumors has been shown among certain strains of $\mathrm{H}-2^{\mathrm{k}}$ expressing mice $(58,59)$. A previously identified $\mathrm{PyV}$ susceptibility gene $\left(P y v^{S}\right)$ (60) was later identified to encode the Sag from $M t v-7$ among $\mathrm{H}-2^{\mathrm{k}}$ mice $(\mathrm{C} 3 \mathrm{H} / \mathrm{BiDa}$ mice) resulting in the intrathymic deletion of TCR V $\beta 6$ expressing T cell populations (59). Among other mechanisms (61), preferential usage of $\mathrm{H}-2^{\mathrm{k}}$-restricted $\mathrm{CD} 8^{+} \mathrm{T}$ cells expressing TCR V $\beta 6$ that were specific for an immunodominant peptide derived from the viral middle $\mathrm{T}$ protein were demonstrated to provide the necessary antitumor immunity against PyV (62). Susceptibility to $\mathrm{PyV}$ is transmitted as a dominant trait due to the requirement of only a single copy of the superantigen being necessary for the deletion of $\mathrm{T}$ cells expressing specific V $\beta$ TCRs. $\mathrm{H}-2^{\mathrm{k}}$-identical $\mathrm{C} 57 \mathrm{BR} / \mathrm{cdJ}$ (BR mice) retain this cytotoxic CD8 ${ }^{+}$TCR V $\beta 6$ population due to the lack of $M t v-7$ and are therefore highly resistant to tumor development.

$M t v-7$ has also been shown to influence the immune response among $\mathrm{H}-2^{\mathrm{d}}$-expressing mice in a murine model of aggressive lymphoma. Although DBA/2 and B10.D2 strains of mice are syngeneic at the MHC and therefore immunologically compatible, they demonstrate varied immune response and outcome upon challenge with the highly malignant DBA/2-derived ESb cell line (63). B10.D2 mice are able to prevent metastasis of such tumors by generating and sustaining a sufficient humoral and cellular immune response. This response is evident by the increased sensitivity of B10.D2 following irradiation or depletion of $\mathrm{CD}^{+}$and $\mathrm{CD} 8^{+} \mathrm{T}$ cells (64). In contrast, naïve DBA/2 mice are highly susceptible to ESb-induced lymphoma (65). The generation of recombinant inbred (RI) mouse strains from the cross of B10.D2 and DBA/2 facilitated the identification of potential genes segregating with ESb-related tumor susceptibility and resistance (63). Genotyping for $M t v$ among several of the tumor-resistant RI strains revealed similarity to the parental DBA/2 strain except for the loss of a particular LTR that corresponded to the $M t v-7$ provirus. It was further demonstrated that ESb tumor cells themselves express proviral $M t v-7$ at both the mRNA and protein level (66). Instead of inducing anergy among the Sag-reactive cells, the ESb tumor-associated $M t v$-7-encoded Sag was demonstrated to induce activation of Sag-specific cytotoxic T lymphocytes. TCR V $\beta 6$ cells were demonstrated to facilitate specific killing of tumor cells expressing the endogenous $M t v-7$ in vitro. Furthermore, treatment of tumorbearing DBA/ 2 mice with TCR V $\beta 6$ T cells from naïve B10.D2 mice led to a significant increase in survival and concurrent reduction in tumor growth (66). It is important to note that the reduction in tumor growth and delay in death lasted only 10 days, suggesting the potential and eventual loss of the TCR V $\beta 6$ T cell population. Therefore, in models of both $\mathrm{PyV}$ and ESb-induced lymphoma, the presence of $M t v-7$ affords a selective disadvantage in terms of deleting a protective population of lymphocytes that are necessary for tumor immunity. 
In contrast to the deletion of Sag-reactive T cells, $M t v$-encoded Sag may further modulate tumor susceptibility via activation of Sag-reactive T cells. Spontaneous reticulum cell sarcoma (RCS), a form of B cell lymphoma, has been observed to arise in $>90 \%$ of SJL mice older than 12 months of age. The development of such RCS requires the presence of host $\mathrm{T}$ cells and specifically that of $\mathrm{T}$ cell-derived cytokines, such as IL-5 and IFN- $\gamma$ (67, 68). The strong proliferative response of previously unsensitized $\mathrm{CD}^{+} \mathrm{T}$ cells to RCS cells (69) and the biased usage of such responding cells expressing TCR V $\beta 16$ imply a role for superantigen in this model (70). CD4 ${ }^{+}$TCR V $\beta 16$ cells have been shown to be capable of supporting RCS growth via the production of IL-2, IL-4, and IL-5. Additional analysis revealed the high expression of a novel MMTV-LTR among mRNA from RCS cells (70). It was subsequently determined that the B cell lymphomas of SJL mice contained Mtv-29, which via the Mtv-29encoded Sag were capable of stimulating TCR V $\beta 16$ cells that are required to support the development of spontaneous B cell lymphomagenesis (71).

Although a majority of the research examining the role of $M t v$ in modulation of the immune response has mainly focused on Sag-dependent processes, evidence does exist to support $M t v$ associated, Sag-independent mechanisms. BALB/c mice harbor three distinct $M t v(M t v-6,-8$, and -9) all on separate chromosomes, which in the context of MHC class II I-E induce intrathymic deletion of reactive T cells expressing TCR V $\beta 3,5,11$, and 12 . The generation of BALB/c congenic mice lacking all endogenous $M t v$ (BALB/Mtv-null) enabled the unique opportunity to examine the influence of $M t v$ on host response to a variety of models (72). In the absence of endogenous $M t v$, the incidence of mammary tumors in response to exogenous MMTV infection was reduced from $100 \%$ (in $\mathrm{BALB} / \mathrm{c}$ ) to $10 \%$ (in $\mathrm{BALB} / M t v$-null). This drastic reduction in tumor incidence was independent of the infection route, whether milk-borne infection or following intraperitoneal injection of a stable cell line expressing the infectious cloned MMTV provirus. Unlike some mouse strains that demonstrate resistance to exogenous MMTV infection via the production of neutralizing antibodies (73), such was not the case with the BALB/Mtv-null mice. BALB/Mtv-null mice also demonstrated resistance to infection with the MMTV variant type $B$ leukemogenic virus (TBLV) (74), which due to a truncated Sag protein lacks the ability to induced Sag-mediated $\mathrm{T}$ cell deletion and thereby induces $\mathrm{T}$ cell lymphoma rather than MMTV-induced mammary cancers.

The $\mathrm{C} 3 \mathrm{H}$ strain of MMTV that was shown to have reduced capacity to induce tumorigenesis in BALB/Mtv-null mice (72) encodes a weak Sag resulting in a slow and marginal deletion of $\mathrm{CD}^{+}{ }^{+} \mathrm{T}$ cells expressing the C3H Sag-reactive TCR V $\beta 14$ (48). This would suggest that endogenous $M t v$-encoded Sag are necessary during the early stages of infection for exogenous Sag presentation and cognate $\mathrm{T}$ cell deletion. In contrast to $\mathrm{C} 3 \mathrm{H}$ MMTV, infection with FM-MMTV, which encodes a stronger Sag $(75,76)$ and therefore results in a much larger response by the cognate TCR V $\beta 8.2^{+}$population, resulted in a similar magnitude and kinetics of Sag response between BALB/c and BALB/Mtv-null mice. These findings imply that the extent of deletion associated with the exogenous MMTV-encoded Sag dictates the impact of endogenous Sag during MMTV infection. While endogenous Sag appear essential during the early stages of infection with C3H-MMTV, a stronger Sag such as the FMMMTV strain can overcome this requirement in terms of establishing the initial infection. Regardless of this early and initial infectivity, the absence of $M t v$ in BALB/Mtv-null mice affords them high resistance to FM-MMTV-induced tumorigenesis and such mice are further incapable of transmitting the virus via their milk (76).

\section{INFLUENCE OF ENDOGENOUS Mtv ON INFECTION}

In the experimental murine model of Leishmania major infection, differences in susceptibility have been attributed to the host's ability to generate a sufficient Th1-biased, IFN- $\gamma$-dominated, CD4 ${ }^{+}$ $\mathrm{T}$ cell response (77). This is most evident upon analysis of the highly susceptible and Th2/IL-4-prone BALB/c strain compared to the highly resistant $\mathrm{C} 57 \mathrm{BL} / 6$ strain that is prototypical of a Th1/IFN- $\gamma$ response. Although certainly much more resistant to disease compared to the $\mathrm{BALB} / \mathrm{c}$ strain, the $\mathrm{CBA} / \mathrm{CaJ}$ and $\mathrm{CBA} / \mathrm{J}$ strains of mice differ in their responses to $L$. major infection. In contrast to $\mathrm{CBA} / \mathrm{CaJ}$ mice that develop only transient lesions upon infection, persistent inflammatory lesions and 10fold higher parasite density are observed in CBA/J mice (78). A quantitative reduction in the production of IFN- $\gamma$ in the CBA/J was determined to account for the persistent lesions upon infection. This reduction in cytokine production further correlated with the presence of $M t v-7$ in the CBA/J strain that is absent in the CBA/CaJ mice. However, unlike the above models of PyV and ESb-induced lymphoma, Mtv-7-specific TCR V $\beta 6$ T cells do not constitute the predominant responding population during $L$. major infection. Furthermore, the overall magnitude and heterogeneity of the $\mathrm{CD} 4^{+} \mathrm{T}$ cell response was similar between the two strains (78). Such findings would suggest that $\mathrm{T}$ cells in general, regardless of their TCR V $\beta$ repertoire commit somewhat poorly to a Th1-biased, IFN- $\gamma$-producing subset in the presence of $M t v-7$ during leishmaniasis. This L. major-specific effect in the presence of $M t v-7$ was determined to be mediated via alteration of the $\mathrm{T}$ cell priming ability of antigen presenting cells. Although no difference was observed in L. major-infected, bone marrow-derived dendritic cells (BMDCs) between CBA/CaJ and $\mathrm{CBA} / \mathrm{J}$ in terms of their expression of various cell surface and co-stimulatory markers, $\mathrm{CD} 4^{+} \mathrm{T}$ cells from CBA/J mice did produce increased IFN- $\gamma$ if primed in the presence of L. majorinfected BMDCs from CBA/CaJ mice compared to their own BMDCs (78). Since impairment of the CBA/J immune response is not due to a specific TCR V $\beta$ subset, these findings would suggest a $M t v$-7-dependent, Sag-independent mechanism responsible for modulating $\mathrm{T}$ cell priming during the pathogenesis of leishmaniasis.

The murine model of Plasmodium berghei ANKA infection constitutes a widely used model that reflects some experimental similarities to that of human cerebral malaria (CM). The neurological symptoms of genetically susceptible mice infected with $P$. berghei ANKA have been shown to be immune mediated, mainly dependent on $\mathrm{CD}^{+}$and $\mathrm{CD}^{+} \mathrm{T}$ cells $(79,80)$. 
In this model, the high production of Th1-derived cytokines, including IFN- $\gamma$ and TNF- $\alpha$, via interferon regulatory factor- 1 (IRF-1) has been implicated in malarial neuropathogenesis (81, 82). The peripheral expansion of a restricted $T$ cell population expressing TCR V $\beta 8.1$ and V $\beta 8.2$ was observed in the highly susceptible B10.D2 $\left(\mathrm{H}-2^{\mathrm{d}}\right)$ strain that manifest severe neurological symptoms but not in infected mice that failed to develop CM. The occurrence of CM was significantly reduced following treatment with a monoclonal antibody against TCR V $\beta 8.1$ specific T cells. Furthermore, the endogenous presence of $M t v-7$ in congenic BALB.D2 mice, or the exogenous counterpart MMTV-SW that encodes the same Sag as Mtv-7 and is present in BALB.SW mice, results in Sag-mediated deletion or anergy of a variety of $\mathrm{V} \beta$-specific populations including $\mathrm{V} \beta 8.1$ that has been demonstrated to provide protection against CM (83). To investigate whether the presence of $M t v-7$ was sufficient to induce resistance to $\mathrm{CM}$, RI strains derived from a cross between the susceptible $\mathrm{BALB} / \mathrm{c}$ (negative for $M t v-7$ ) and resistant DBA/2 (positive for $M t v-7)$ were examined for their response during P. berghei ANKA infection. A strong correlation was identified between the presence of $M t v-7$ and protection against neuropathogenesis of CM (84). The similar levels of parasitemia observed between Mtv$7^{+}$and $M t v-7^{-}$mice would suggest that integration of the viral genome did not have any effect on at least the initial stages of parasite growth and development (84). Overall, it was concluded that deletion of $\mathrm{T}$ cells expressing TCR V $\beta 8.1$ among $\mathrm{H}-2^{\mathrm{d}}$ expressing strains of mice, whether via the exogenous or endogenous presence of $M t v-7$-encoded Sag was sufficient to confer resistance to CM. Unlike the models of PyV, ESb-induced lymphoma, and L. major infection, in which the presence of Mtv confers a selective disadvantage to the host and increases susceptibility, $M t v$ appears to provide protection during the neuropathogenesis of P. berghei ANKA infection, by an as of yet unidentified mechanism.

In addition to modulation of the conventional population of $\mathrm{CD}^{+}$and $\mathrm{CD}^{+}{ }^{+} \mathrm{T}$ cells, $\mathrm{Mt} v$ have been demonstrated to influence the immune system during viral infection via expansion of a particular subset of $\mathrm{CD} 4^{+} \mathrm{T}$ cells expressing the transcription factor Foxp3. Murine infection with the clone 13 isolate of lymphocytic choriomeningitis virus (LCMV) represents a model of chronic viral infection, in which $\mathrm{T}$ cell exhaustion results in infection virtually for life $(85,86)$. Infection of mice with LCMV clone 13 resulted in the selective expansion of a TCR V $\beta$ specific population of Foxp $3^{+}$regulatory T cells (Treg) (87). The expansion of TCR V $\beta 5^{+}$Treg was determined to be MHC class IIdependent, CD4-independent, and secondary to stimulation by the $M t v-9$-encoded Sag. Treg play a key role in immune suppression and control of organ-specific autoimmune diseases via a variety of mechanisms. Whether this specific $M t v$-encoded Sagmediated expansion of Treg influences the pathogenesis of viral or other infectious agents remains to be determined. Nevertheless, it does demonstrate the wide range of influence Mtv has on the immune system, influencing both effector and suppressor lymphocyte populations.

In addition to the reduction in tumorigenicity via both a Sag-dependent and Sag-independent manner, the absence of Mtv provided further resistance to inoculation with the gram-negative bacterium Vibrio cholerae, as demonstrated by decreased bacterial replication and mortality in BALB/Mtv-null mice. However, the absence of Mtv did not provide absolute resistance to bacterial challenge, as infection with Salmonella typhimurium resulted in similar mortality between BALB/c and BALB/Mtv-null mice. The reintroduction of any single $M t v$ provirus into the BALB/Mtvnull mice (generating congenic mice positive for either $M t v-6$, -8 , or -9 ) was sufficient to restore susceptibility to both select viral (MMTV-induced mammary tumors) as well as bacterial ( $V$. cholera) challenge. Interestingly, the difference in susceptibility to $V$. cholera was observed as early as $48 \mathrm{~h}$ following infection, suggesting $M t v$ may function to regulate processes of innate immunity. However, the exact mechanism for this increased susceptibility to disparate pathogens among mice expressing at least one or more $M t v$ remains to be elucidated. One clue may resolve around the unique fact that unlike $M t v-8$ and $-9, M t v-6$ lacks a $>6 \mathrm{~kb}$ portion of sequence encoding most of the viral Gag, Env, and Pol proteins. $M t v-6$ does encode functional Sag, which would suggest that a Sag-mediated or as of yet unidentified $M t v$-encoded product may modulate an immune response that is uniquely shared between MMTV and V. cholera.

\section{INFLUENCE OF ENDOGENOUS Mtv ON IMMUNITY}

In addition to the above models, $M t v-7$ was implicated to modulate the immune response during the progression of graft-versushost disease (GVHD). In this model, the transfer of either parental C57BL/6 or DBA/2 lymphoid cells into F1 offspring (B6D2F1) yields opposing disease outcome. Donor lymphoid cells from C57BL/6, which are associated with a Th1-biased, IFN- $\gamma$-mediated cytokine response, induce an acute form of GVHD. On the other hand, the Th2-prone, IL-4-mediated response characteristic of DBA/2 yields a more chronic disease. Although C57BL/6 and DBA/2 differ in MHC haplotype, such a difference between the induction of an acute and chronic response was attributed to a non-MHC-related mechanism (88). Mtv-7, or that of a closely linked locus to $M t v-7$ was implicated in the relative development of acute and chronic GVDH based on data from congenic C57BL/6 mice containing DBA/2-derived alleles at the region surrounding $M t v-7$ on chromosome 1 (89). When lymphoid cells from the congenic $\mathrm{C} 57 \mathrm{BL} / 6\left(\mathrm{H}-2^{\mathrm{d}}\right)$ were transferred to recipient $\mathrm{B} 6 \mathrm{D} 2 \mathrm{~F} 1$ mice, the mice developed signs more consistent with that of chronic GVDH than that of the acute disease normally associated after transfer of C57BL/6 cells (89). Furthermore, transfer of the congenic $\mathrm{C} 57 \mathrm{BL} / 6$ lymphoid cells containing the DBA/2derived alleles around $M t v-7$ resulted in decreased expression levels of IFN- $\gamma$ and increased levels of IL- 4 compared to the control C57BL/6 transfer. Although these data would suggest a $M t v-7$-mediated influence on disease outcome, depletion of Mtv7 -encoded Sag-reactive cells from the donor population did not impact the development of acute GVHD. As such, the possibility remains that a locus near that of $M t v-7$ on chromosome 1 can influence host immune response and the eventual outcome of GVHD.

Collectively, the above models demonstrate the range of influence endogenous Mtv have in their ability to modulate host 



FIGURE 1 | Influence of endogenous Mtv on host response to infection and disease. Potential mechanisms by which endogenous Mtv influence host response during infection and disease. Solid lines represent known mechanisms, dashed lines represent potential mechanisms. Question marks represent outcomes that remain to be determined. susceptibility to a variety of infections and diseases in seemingly opposite manners (Figure 1). In the case of PyV infection and ESbinduced lymphoma, $M t v$-encoded Sag induce deletion of tumorreactive $\mathrm{T}$ cells thereby facilitating tumor development and progression. At the same time, $M t v$-mediated activation/stimulation of Sag-reactive $\mathrm{T}$ cells appears to promote neuropathogenesis during $P$. berghei ANKA infection as well as induce B cell lymphoma. In addition to conventional T cells, $M t v$ has been shown to modulate the population of Foxp $3^{+}$regulatory $\mathrm{T}$ cells via a Sag-dependent manner during the course of chronic viral infection. The activation of Treg can combat and limit the extent of autoimmune disease while at the same time facilitate tumor progression by suppressing tumor immunity. The potential ability to modulate such a dynamic population of $\mathrm{T}$ cells can therefore have important implications on host outcome. In addition to Sag-dependent mechanisms, other as of yet unidentified genes from the Mtv provirus may be capable of influencing Sagindependent immune responses, such as during $L$. major infection. Furthermore, $M t v$-mediated influence may not be restricted to the adaptive immune system, as evidence using BALB/Mtvnull mice may suggest modulation of potential innate immune responses.

\section{CONCLUSION}

The co-evolution of Mtv and its murine host has allowed ample time for the virus to develop various mechanisms to modulate immune regulatory mechanisms. While many endogenous proviral gene sequences have acquired mutations that have led them to be non-functional, Sag expression has remained intact suggesting some benefit for the host. Recent advances suggest that these advantages go beyond the initial idea that Mtv exist solely as a way to prevent exogenous MMTV-induced mammary carcinoma. While the exact mechanisms by which Mtv function in all of these various models are not fully known, further insight into how endogenous $M t v$, and in particular Mtv Sag, influence the immune system can provide potential benefit. Such knowledge may prove useful for therapeutic modifications of lymphocytes using retroviral-based vectors for gene therapy (90). In addition, although there are differences in terms of the activity of viral and bacterial superantigens, the knowledge gained from endogenous retroviruses may prove potentially useful for the targeting of Sagreactive lymphocytes to tumor cells (91). Ultimately, understanding the mechanisms underlying retroviral integration and interaction with the immune system could provide benefits to a multitude of disease processes, including infectious diseases and cancers. 


\section{REFERENCES}

1. Tristem M. Identification and characterization of novel human endogenous retrovirus families by phylogenetic screening of the human genome mapping project database. J Virol (2000) 74(8):3715-30. doi:10.1128/JVI.74.8.3715-3730. 2000

2. Polavarapu N, Bowen NJ, McDonald JF. Identification, characterization and comparative genomics of chimpanzee endogenous retroviruses. Genome Biol (2006) 7(6):R51. doi:10.1186/gb-2006-7-6-r51

3. Huda A, Polavarapu N, Jordan IK, McDonald JF. Endogenous retroviruses of the chicken genome. Biol Direct (2008) 3:9. doi:10.1186/1745-6150-3-9

4. Stocking C, Kozak CA. Murine endogenous retroviruses. Cell Mol Life Sci (2008) 65(21):3383-98. doi:10.1007/s00018-008-8497-0

5. Kozak C, Peters G, Pauley R, Morris V, Michalides R, Dudley J, et al. A standardized nomenclature for endogenous mouse mammary tumor viruses. J Virol (1987) 61(5):1651-4.

6. Karapetian O, Shakhov AN, Kraehenbuhl JP, Acha-Orbea H. Retroviral infection of neonatal Peyer's patch lymphocytes: the mouse mammary tumor virus model. J Exp Med (1994) 180(4):1511-6. doi:10.1084/jem.180.4.1511

7. Hook LM, Agafonova Y, Ross SR, Turner SJ, Golovkina TV. Genetics of mouse mammary tumor virus-induced mammary tumors: linkage of tumor induction to the gag gene. J Virol (2000) 74(19):8876-83. doi:10.1128/JVI.74.19.88768883.2000

8. Lee BK, Eicher EM. Segregation patterns of endogenous mouse mammary tumor viruses in five recombinant inbred strain sets. J Virol (1990) 64(9):4568-72.

9. Morris VL, Medeiros E, Ringold GM, Bishop JM, Varmus HE. Comparison of mouse mammary tumor virus-specific DNA in inbred, wild and Asian mice, and in tumors and normal organs from inbred mice. J Mol Biol (1977) 114(1):73-91. doi:10.1016/0022-2836(77)90284-4

10. van Nie R, Verstraeten AA. Studies of genetic transmission of mammary tumour virus by C3Hf mice. Int J Cancer (1975) 16(6):922-31. doi:10.1002/ ijc. 2910160606

11. Michalides R, van Deemter L, Nuss RR, van Nie R. Identification of the Mtv-2 gene responsible for the early appearance of mammary tumors in the GR mouse by nucleic acid hybridization. Proc Natl Acad Sci U S A (1978) 75(5):2368-72. doi:10.1073/pnas.75.5.2368

12. Michalides R, van Nie R, Nusse R, Hynes NE, Groner B. Mammary tumor induction loci in GR and DBAf mice contain one provirus of the mouse mammary tumor virus. Cell (1981) 23(1):165-73. doi:10.1016/0092-8674(81) 90281-6

13. Ross SR. MMTV infectious cycle and the contribution of virus-encoded proteins to transformation of mammary tissue. J Mammary Gland Biol Neoplasia (2008) 13(3):299-307. doi:10.1007/s10911-008-9090-8

14. Acha-Orbea H, Shakhov AN, Scarpellino L, Kolb E, Muller V, Vessaz-Shaw A, et al. Clonal deletion of $\mathrm{V}$ beta 14-bearing $\mathrm{T}$ cells in mice transgenic for mammary tumour virus. Nature (1991) 350(6315):207-11. doi:10.1038/350207a0

15. Choi Y, Kappler JW, Marrack P. A superantigen encoded in the open reading frame of the 3' long terminal repeat of mouse mammary tumour virus. Nature (1991) 350(6315):203-7. doi:10.1038/350203a0

16. Mertz JA, Lozano MM, Dudley JP. Rev and Rex proteins of human complex retroviruses function with the MMTV Rem-responsive element. Retrovirology (2009) 6:10. doi:10.1186/1742-4690-6-10

17. Indik S, Gunzburg WH, Salmons B, Rouault F. A novel, mouse mammary tumor virus encoded protein with Rev-like properties. Virology (2005) 337(1):1-6. doi:10.1016/j.virol.2005.03.040

18. Mertz JA, Simper MS, Lozano MM, Payne SM, Dudley JP. Mouse mammary tumor virus encodes a self-regulatory RNA export protein and is a complex retrovirus. J Virol (2005) 79(23):14737-47. doi:10.1128/JVI.79.23.14737-14747. 2005

19. Salmons B, Knedlitschek G, Kennedy N, Groner B, Ponta H. The endogenous mouse mammary tumour virus locus Mtv-8 contains a defective envelope gene. Virus Res (1986) 4(4):377-89. doi:10.1016/0168-1702(86)90084-5

20. Kuo WL, Vilander LR, Huang M, Peterson DO. A transcriptionally defective long terminal repeat within an endogenous copy of mouse mammary tumor virus proviral DNA. J Virol (1988) 62(7):2394-402.

21. Cho K, Ferrick DA, Morris DW. Structure and biological activity of the subgenomic Mtv-6 endogenous provirus. Virology (1995) 206(1):395-402. doi:10.1016/S0042-6822(95)80055-7
22. Bittner JJ. Some possible effects of nursing on the mammary gland tumor incidence in mice. Science (1936) 84(2172):162. doi:10.1126/science.84.2172.162

23. Bittner JJ. The milk-influence of breast tumors in mice. Science (1942) 95(2470):462-3. doi:10.1126/science.95.2470.462

24. Beutner U, Kraus E, Kitamura D, Rajewsky K, Huber BT. B cells are essential for murine mammary tumor virus transmission, but not for presentation of endogenous superantigens. J Exp Med (1994) 179(5):1457-66. doi:10.1084/jem. 179.5.1457

25. Rassa JC, Meyers JL, Zhang Y, Kudaravalli R, Ross SR. Murine retroviruses activate B cells via interaction with toll-like receptor 4. Proc Natl Acad Sci U S A (2002) 99(4):2281-6. doi:10.1073/pnas.042355399

26. Golovkina TV, Chervonsky A, Dudley JP, Ross SR. Transgenic mouse mammary tumor virus superantigen expression prevents viral infection. Cell (1992) 69(4):637-45. doi:10.1016/0092-8674(92)90227-4

27. Pullen AM, Wade T, Marrack P, Kappler JW. Identification of the region of T cell receptor beta chain that interacts with the self-superantigen MIs-1a. Cell (1990) 61(7):1365-74. doi:10.1016/0092-8674(90)90700-O

28. Acha-Orbea H, Scarpellino L, Shakhov AN, Held W, MacDonald HR. Inhibition of mouse mammary tumor virus-induced $\mathrm{T}$ cell responses in vivo by antibodies to an open reading frame protein. J Exp Med (1992) 176(6):1769-72. doi:10.1084/jem.176.6.1769

29. Yazdanbakhsh K, Park CG, Winslow GM, Choi Y. Direct evidence for the role of $\mathrm{COOH}$ terminus of mouse mammary tumor virus superantigen in determining T cell receptor V beta specificity. J Exp Med (1993) 178(2):737-41. doi:10.1084/jem.178.2.737

30. Maillard I, Erny K, Acha-Orbea H, Diggelmann H. A V beta 4-specific superantigen encoded by a new exogenous mouse mammary tumor virus. Eur J Immunol (1996) 26(5):1000-6. doi:10.1002/eji.1830260507

31. Chervonsky AV, Xu J, Barlow AK, Khery M, Flavell RA, Janeway CA Jr. Direct physical interaction involving CD40 ligand on T cells and CD40 on B cells is required to propagate MMTV. Immunity (1995) 3(1):139-46. doi:10.1016/ 1074-7613(95)90166-3

32. Held W, Shakhov AN, Izui S, Waanders GA, Scarpellino L, MacDonald HR, et al. Superantigen-reactive CD4+ T cells are required to stimulate B cells after infection with mouse mammary tumor virus. J Exp Med (1993) 177(2):359-66. doi:10.1084/jem.177.2.359

33. Tsubura A, Inaba M, Imai S, Murakami A, Oyaizu N, Yasumizu R, et al. Intervention of T-cells in transportation of mouse mammary tumor virus (milk factor) to mammary gland cells in vivo. Cancer Res (1988) 48(22):6555-9.

34. Squartini F, Olivi M, Bolis GB. Mouse strain and breeding stimulation as factors influencing the effect of thymectomy on mammary tumorigenesis. Cancer Res (1970) 30(7):2069-72.

35. Wrona T, Dudley JP. Major histocompatibility complex class II I-Eindependent transmission of C3H mouse mammary tumor virus. J Virol (1996) 70(2):1246-9.

36. Nusse R, Varmus HE. Many tumors induced by the mouse mammary tumor virus contain a provirus integrated in the same region of the host genome. Cell (1982) 31(1):99-109. doi:10.1016/0092-8674(82)90409-3

37. Dickson C, Peters G. Potential oncogene product related to growth factors. Nature (1987) 326(6116):833. doi:10.1038/326833a0

38. Faschinger A, Rouault F, Sollner J, Lukas A, Salmons B, Gunzburg WH, et al. Mouse mammary tumor virus integration site selection in human and mouse genomes. J Virol (2008) 82(3):1360-7. doi:10.1128/JVI.02098-07

39. Dickson C, Smith R, Brookes S, Peters G. Tumorigenesis by mouse mammary tumor virus: proviral activation of a cellular gene in the common integration region int-2. Cell (1984) 37(2):529-36. doi:10.1016/0092-8674(84)90383-0

40. Nusse R, van Ooyen A, Cox D, Fung YK, Varmus H. Mode of proviral activation of a putative mammary oncogene (int-1) on mouse chromosome 15. Nature (1984) 307(5947):131-6. doi:10.1038/307131a0

41. Peters G, Brookes S, Smith R, Placzek M, Dickson C. The mouse homolog of the hst/k-FGF gene is adjacent to int-2 and is activated by proviral insertion in some virally induced mammary tumors. Proc Natl Acad Sci U S A (1989) 86(15):5678-82. doi:10.1073/pnas.86.15.5678

42. Festenstein H. Immunogenetic and biological aspects of in vitro lymphocyte allotransformation (MLR) in the mouse. Transplant Rev (1973) 15:62-88.

43. Woodland D, Happ MP, Bill J, Palmer E. Requirement for cotolerogenic gene products in the clonal deletion of I-E reactive T cells. Science (1990) 247(4945):964-7. doi:10.1126/science.1968289 
44. Dyson PJ, Knight AM, Fairchild S, Simpson E, Tomonari K. Genes encoding ligands for deletion of $\mathrm{V}$ beta $11 \mathrm{~T}$ cells cosegregate with mammary tumour virus genomes. Nature (1991) 349(6309):531-2. doi:10.1038/349531a0

45. Frankel WN, Rudy C, Coffin JM, Huber BT. Linkage of Mls genes to endogenous mammary tumour viruses of inbred mice. Nature (1991) 349(6309):526-8. doi:10.1038/349526a0

46. Woodland DL, Happ MP, Gollob KJ, Palmer E. An endogenous retrovirus mediating deletion of alpha beta T cells? Nature (1991) 349(6309):529-30. doi: $10.1038 / 349529 \mathrm{a} 0$

47. Kappler JW, Roehm N, Marrack P. T cell tolerance by clonal elimination in the thymus. Cell (1987) 49(2):273-80. doi:10.1016/0092-8674(87)90568-X

48. Marrack P, Kushnir E, Kappler J. A maternally inherited superantigen encoded by a mammary tumour virus. Nature (1991) 349(6309):524-6. doi:10.1038/ 349524a0

49. Kappler JW, Wade T, White J, Kushnir E, Blackman M, Bill J, et al. A T cell receptor V beta segment that imparts reactivity to a class II major histocompatibility complex product. Cell (1987) 49(2):263-71. doi:10.1016/0092-8674(87)90567-8

50. Beutner U, Frankel WN, Cote MS, Coffin JM, Huber BT. Mls-1 is encoded by the long terminal repeat open reading frame of the mouse mammary tumor provirus Mtv-7. Proc Natl Acad Sci U S A (1992) 89(12):5432-6. doi:10.1073/pnas.89.12.5432

51. Winslow GM, Scherer MT, Kappler JW, Marrack P. Detection and biochemical characterization of the mouse mammary tumor virus 7 superantigen (Mls-1a). Cell (1992) 71(5):719-30. doi:10.1016/0092-8674(92)90549-R

52. Scherer MT, Ignatowicz L, Pullen A, Kappler J, Marrack P. The use of mammary tumor virus (Mtv)-negative and single-Mtv mice to evaluate the effects of endogenous viral superantigens on the T cell repertoire. J Exp Med (1995) 182(5):1493-504. doi:10.1084/jem.182.5.1493

53. Acha-Orbea H, Held W, Waanders GA, Shakhov AN, Scarpellino L, Lees RK, et al. Exogenous and endogenous mouse mammary tumor virus superantigens. Immunol Rev (1993) 131:5-25. doi:10.1111/j.1600-065X.1993.tb01527.x

54. Scherer MT, Ignatowicz L, Winslow GM, Kappler JW, Marrack P. Superantigens: bacterial and viral proteins that manipulate the immune system. Annu Rev Cell Biol (1993) 9:101-28. doi:10.1146/annurev.cb.09.110193.000533

55. Golovkina TV, Prescott JA, Ross SR. Mouse mammary tumor virus-induced tumorigenesis in sag transgenic mice: a laboratory model of natural selection. J Virol (1993) 67(12):7690-4.

56. van Nie R, de Moes J. Development of a congeneic line of the GR mouse strain without early mammary tumours. Int J Cancer (1977) 20(4):588-94. doi:10.1002/ijc.2910200417

57. Dawe CJ, Freund R, Mandel G, Ballmer-Hofer K, Talmage DA, Benjamin TL. Variations in polyoma virus genotype in relation to tumor induction in mice. Characterization of wild type strains with widely differing tumor profiles. Am J Pathol (1987) 127(2):243-61.

58. Freund R, Dubensky T, Bronson R, Sotnikov A, Carroll J, Benjamin T. Polyoma tumorigenesis in mice: evidence for dominant resistance and dominant susceptibility genes of the host. Virology (1992) 191(2):724-31. doi:10.1016/00426822(92)90248-N

59. Lukacher AE, Ma Y, Carroll JP, Abromson-Leeman SR, Laning JC, Dorf ME, et al. Susceptibility to tumors induced by polyoma virus is conferred by an endogenous mouse mammary tumor virus superantigen. J Exp Med (1995) 181(5):1683-92. doi:10.1084/jem.181.5.1683

60. Lukacher AE, Freund R, Carroll JP, Bronson RT, Benjamin TL. Pyvs: a dominantly acting gene in $\mathrm{C} 3 \mathrm{H} / \mathrm{BiDa}$ mice conferring susceptibility to tumor induction by polyoma virus. Virology (1993) 196(1):241-8. doi:10.1006/viro.1993.1472

61. Velupillai P, Sung CK, Andrews E, Moran J, Beier D, Kagan J, et al. Polymorphisms in toll-like receptor 4 underlie susceptibility to tumor induction by the mouse polyomavirus. J Virol (2012) 86(21):11541-7. doi:10.1128/JVI.01614-12

62. Lukacher AE, Wilson CS. Resistance to polyoma virus-induced tumors correlates with CTL recognition of an immunodominant $\mathrm{H}$-2Dk-restricted epitope in the middle T protein. J Immunol (1998) 160(4):1724-34.

63. Schirrmacher V, Beutner U, Bucur M, Umansky V, Rocha M, von Hoegen P. Loss of endogenous mouse mammary tumor virus superantigen increases tumor resistance. J Immunol (1998) 161(2):563-70.

64. Schirrmacher V, Zangemeisterwittke U. Gamma-irradiation suppresses T-cell mediated protective immunity against a metastatic tumor in the afferent phase of the immune-response but enhances it in the efferent phase when given before immune cell transfer. Int J Oncol (1994) 4(2):335-46.
65. Bosslet K, Schirrmacher V. Escape of metastasizing clonal tumor cell variants from tumor-specific cytolytic T lymphocytes. J Exp Med (1981) 154(2):557-62. doi:10.1084/jem.154.2.557

66. Schirrmacher V, Muerkoster S, Bucur M, Umansky V, Rocha M. Breaking tolerance to a tumor-associated viral superantigen as a basis for graft-versusleukemia reactivity. Int J Cancer (2000) 87(5):695-706. doi:10.1002/10970215(20000901)87:5<695::AID-IJC12>3.0.CO;2-B

67. Lasky JL, Ponzio NM, Thorbecke GJ. Characterization and growth factor requirements of SJL lymphomas. I. Development of a B cell growth factordependent in vitro cell line, cRCS-X. J Immunol (1988) 140(2):679-87.

68. Lasky JL, Thorbecke GJ. Characterization and growth factor requirements of SJL lymphomas. II. Interleukin 5 dependence of the in vitro cell line, cRCS$\mathrm{X}$, and influence of other cytokines. Eur J Immunol (1989) 19(2):365-71. doi:10.1002/eji.1830190222

69. Ponzio NM, Chapman-Alexander J, Thorbecke GJ. Properties of reticulum cell sarcomas in SJL/J mice VI. Characterization of lymphoid cells that proliferate in response to RCS cells. Cell Immunol (1978) 41(1):157-71. doi:10.1016/S00088749(78)80035-5

70. Tsiagbe VK, Asakawa J, Miranda A, Sutherland RM, Paterson Y, Thorbecke GJ. Syngeneic response to SJL follicular center B cell lymphoma (reticular cell sarcoma) cells is primarily in $\mathrm{V}$ beta $16+\mathrm{CD} 4+\mathrm{T}$ cells. J Immunol (1993) 150(12):5519-28.

71. Sen N, Simmons WJ, Thomas RM, Erianne G, Zhang DJ, Jaeggli NS, et al. METAcontrolled env-initiated transcripts encoding superantigens of murine Mtv29 and Mtv7 and their possible role in B cell lymphomagenesis. J Immunol (2001) 166(9):5422-9.

72. Bhadra S, Lozano MM, Payne SM, Dudley JP. Endogenous MMTV proviruses induce susceptibility to both viral and bacterial pathogens. PLoS Pathog (2006) 2(12):e128. doi:10.1371/journal.ppat.0020128

73. Purdy A, Case L, Duvall M, Overstrom-Coleman M, Monnier N, Chervonsky A, et al. Unique resistance of $\mathrm{I} / \mathrm{LnJ}$ mice to a retrovirus is due to sustained interferon gamma-dependent production of virus-neutralizing antibodies. J Exp Med (2003) 197(2):233-43. doi:10.1084/jem.20021499

74. Mustafa F, Bhadra S, Johnston D, Lozano M, Dudley JP. The type B leukemogenic virus truncated superantigen is dispensable for T-cell lymphomagenesis. J Virol (2003) 77(6):3866-70. doi:10.1128/JVI.77.6.3866-3870.2003

75. Held W, Shakhov AN, Waanders G, Scarpellino L, Luethy R, Kraehenbuhl JP, et al. An exogenous mouse mammary tumor virus with properties of Mls-1a (Mtv-7). J Exp Med (1992) 175(6):1623-33. doi:10.1084/jem.175.6.1623

76. Bhadra S, Lozano MM, Dudley JP. BALB/Mtv-null mice responding to strong mouse mammary tumor virus superantigens restrict mammary tumorigenesis. J Virol (2009) 83(1):484-8. doi:10.1128/JVI.01374-08

77. Reiner SL, Locksley RM. The regulation of immunity to Leishmania major. Annu Rev Immunol (1995) 13:151-77. doi:10.1146/annurev.iy.13.040195. 001055

78. Varanasi V, Mattoo H, Tupperwar NC, Thyagarajan K, Das A, Kumar R, et al. A superantigen interacts with leishmanial infection in antigen-presenting cells to regulate cytokine commitment of responding CD4 T cells. J Infect Dis (2010) 202(8):1234-45. doi:10.1086/656366

79. Grau GE, Piguet PF, Engers HD, Louis JA, Vassalli P, Lambert PH. L3T4+ T lymphocytes play a major role in the pathogenesis of murine cerebral malaria. J Immunol (1986) 137(7):2348-54.

80. Hermsen C, van de Wiel T, Mommers E, Sauerwein R, Eling W. Depletion of CD4+ or CD8+ T-cells prevents Plasmodium berghei induced cerebral malaria in end-stage disease. Parasitology (1997) 114(Pt 1):7-12. doi:10.1017/ S0031182096008293

81. Grau GE, Fajardo LF, Piguet PF, Allet B, Lambert PH, Vassalli P. Tumor necrosis factor (cachectin) as an essential mediator in murine cerebral malaria. Science (1987) 237(4819):1210-2. doi:10.1126/science.3306918

82. Grau GE, Heremans H, Piguet PF, Pointaire P, Lambert PH, Billiau A, et al. Monoclonal antibody against interferon gamma can prevent experimental cerebral malaria and its associated overproduction of tumor necrosis factor. Proc Natl Acad Sci U S A (1989) 86(14):5572-4. doi:10.1073/pnas.86. 14.5572

83. Boubou MI, Collette A, Voegtle D, Mazier D, Cazenave PA, Pied S. T cell response in malaria pathogenesis: selective increase in T cells carrying the TCR V(beta) 8 during experimental cerebral malaria. Int Immunol (1999) 11(9):1553-62. doi:10.1093/intimm/11.9.1553 
84. Gorgette O, Existe A, Boubou MI, Bagot S, Guenet JL, Mazier D, et al. Deletion of $\mathrm{T}$ cells bearing the $\mathrm{V}$ beta8.1 T-cell receptor following mouse mammary tumor virus 7 integration confers resistance to murine cerebral malaria. Infect Immun (2002) 70(7):3701-6. doi:10.1128/IAI.70.7.3701-3706.2002

85. Matloubian M, Concepcion RJ, Ahmed R. CD4+ T cells are required to sustain CD8+ cytotoxic T-cell responses during chronic viral infection. J Virol (1994) 68(12):8056-63.

86. Wherry EJ, Blattman JN, Murali-Krishna K, van der Most R, Ahmed R. Viral persistence alters CD8 T-cell immunodominance and tissue distribution and results in distinct stages of functional impairment. J Virol (2003) 77(8):4911-27. doi:10.1128/JVI.77.8.4911-4927.2003

87. Punkosdy GA, Blain M, Glass DD, Lozano MM, O’Mara L, Dudley JP, et al. Regulatory T-cell expansion during chronic viral infection is dependent on endogenous retroviral superantigens. Proc Natl Acad Sci U S A (2011) 108(9):3677-82. doi:10.1073/pnas.1100213108

88. Van Elven EH, Rolink AG, Veen FV, Gleichmann E. Capacity of genetically different $\mathrm{T}$ lymphocytes to induce lethal graft-versus-host disease correlates with their capacity to generate suppression but not with their capacity to generate anti-F1 killer cells. A non-H-2 locus determines the inability to induce lethal graft-versus-host disease. J Exp Med (1981) 153(6):1474-88.

89. Allen RD, Slayback DL, Harper JM, Aguirre TL, Dobkins JA. A locus closely linked to Mtv7 on mouse chromosome 1 influences development of acute versus chronic graft-versus-host disease in a murine model. Clin Immunol (2000) 95(1 Pt 1):9-19. doi:10.1006/clim.2000.4841
90. Suerth JD, Schambach A, Baum C. Genetic modification of lymphocytes by retrovirus-based vectors. Curr Opin Immunol (2012) 24(5):598-608. doi:10. 1016/j.coi.2012.08.007

91. Sun J, Zhao L, Teng L, Lin F, Zhang H, Li Z, et al. Solid tumor-targeted infiltrating cytotoxic T lymphocytes retained by a superantigen fusion protein. PLoS One (2011) 6(2):e16642. doi:10.1371/journal.pone.0016642

Conflict of Interest Statement: The authors declare that the research was conducted in the absence of any commercial or financial relationships that could be construed as a potential conflict of interest.

Received: 01 July 2013; paper pending published: 10 September 2013; accepted: 10 November 2013; published online: 26 November 2013.

Citation: Holt MP, Shevach EM and Punkosdy GA (2013) Endogenous mouse mammary tumor viruses (Mtv): new roles for an old virus in cancer, infection, and immunity. Front. Oncol. 3:287. doi: 10.3389/fonc.2013.00287

This article was submitted to Molecular and Cellular Oncology, a section of the journal Frontiers in Oncology.

Copyright (c) 2013 Holt, Shevach and Punkosdy. This is an open-access article distributed under the terms of the Creative Commons Attribution License (CC BY). The use, distribution or reproduction in other forums is permitted, provided the original author(s) or licensor are credited and that the original publication in this journal is cited in accordance with accepted academic practice. No use, distribution or reproduction is permitted which does not comply with these terms. 